DNA Library of Life, research article

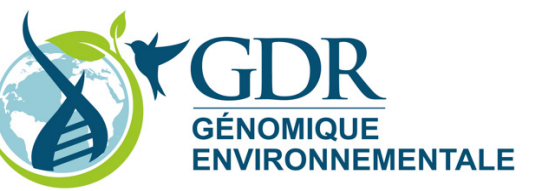

urn:1sid:zoobank.org:pub:1C0EF29F-A413-4198-BFEF-E2A09EFBB89E

\title{
Untangling species identity in gastropods with polymorphic shells in the genus Bolma Risso, 1826 (Mollusca, Vetigastropoda)
}

\author{
Magalie CASTELIN ${ }^{1, *}$, Suzanne T. WILLIAMS ${ }^{2}$, Barbara BUGE ${ }^{3}$, \\ Philippe MAESTRATI ${ }^{4}$, Josie LAMBOURDIÈRE ${ }^{5}$, Tomowo OZAWA ${ }^{6}$, \\ José UTGE ${ }^{7}$, Arnaud COULOUX ${ }^{8}$, Axel ALF $^{9} \&$ Sarah SAMADI $^{10}$ \\ ${ }^{1}$ Fisheries and Oceans Canada, Pacific Biological Station, 3190 Hammond \\ Bay Road, Nanaimo, British Columbia V9T 6N7, Canada. \\ ${ }^{1,4,10}$ ISYEB - UMR 7205 - CNRS, MNHN, UPMC, EPHE, Muséum national \\ d'Histoire naturelle, Département Systématique et Evolution, Sorbonne \\ Universités, CP 26, 57 rue Cuvier, 75231 Paris Cedex 05, France.
}

${ }^{2}$ Department of Zoology, The Natural History Museum, London SW7 5BD, United Kingdom.

${ }^{3}$ Direction des Collections, 55 rue Buffon, CP 51, 75231 Paris Cedex 05, France.

${ }_{5,7,10}$ Service de Systématique Moléculaire, UMS 2700 MNHN - CNRS, Département Systématique et Evolution, Muséum national d'Histoire naturelle, 43 rue Cuvier, 75005 Paris, France.

${ }^{6}$ Department of World Heritage, Cyber University, Nagoya Office, Ikegamicho-2-7-1-203, Chikusa-ku, Nagoya 464-0029, Japan.

${ }^{8}$ GENOSCOPE, Centre National de Séquençage, 2 rue Gaston Crémieux, CP 5706, 91057 Evry Cedex, France.

${ }^{9}$ University of Applied Sciences, Weihenstephan-Triesdorf, 91746 Triesdorf, Germany.

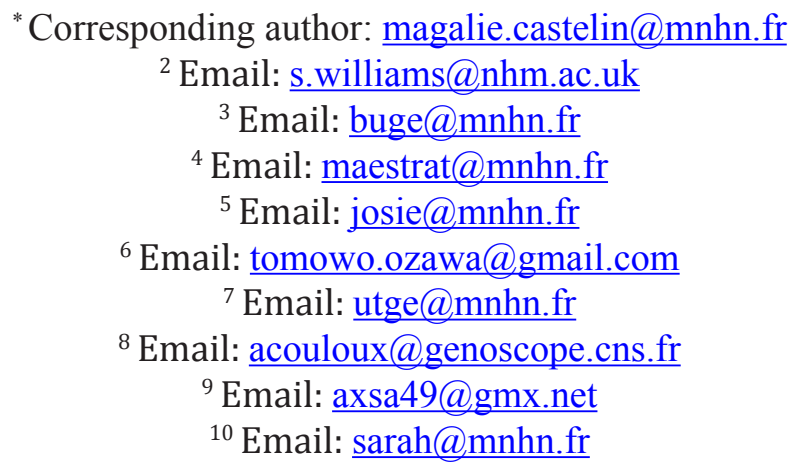

${ }^{1}$ urn:1sid:zoobank.org:author:9464EC90-738D-4795-AAD2-9C6D0FA2F29D

${ }^{2}$ urn:1sid:zoobank.org:author:F860A71B-09B6-4FC9-95F8-E57D4CDF1EC3

${ }^{3}$ urn:1sid:zoobank.org:author:2811430E-BA1E-487E-B361-A7EDC9EE325B

${ }^{4}$ urn:lsid:zoobank.org:author:04A92A39-4B67-4053-94AE-C0F708E0A548

${ }^{5}$ urn:Isid:zoobank.org:author:684FC871-334E-4A61-BD84-EEBDFB4EAA91 ${ }^{6}$ urn:1sid:zoobank.org:author:B7761805-9CB5-4B33-91C2-B496D89B4487

${ }^{7}$ urn:1sid:zoobank.org:author:3888EAFD-B518-4979-A2DF-4A7A1D4B7F89

${ }^{8}$ urn:1sid:zoobank.org:author:423CCAAB-23DE-487A-B245-F9438897E24C 
${ }^{9}$ urn:1sid:zoobank.org:author:2499BA87-6696-4E75-9A99-A5F45E980B8A

${ }^{10}$ urn:lsid:zoobank.org:author:815E7241-54B4-48CB-840B-B30229A96A4E

\begin{abstract}
In shelled molluscs, assigning valid species names to independent evolutionary lineages can be a difficult task. Most original descriptions are based on empty shells and the high levels of variation in shape, color and pattern in some groups can make the shell a poor proxy for species-level identification. The deep-sea gastropod turbinid genus Bolma is one such example, where species-level identification based on shell characters alone is challenging. Here, we show that in Bolma both traditional and molecular taxonomic treatments are associated with a number of pitfalls that can lead to biased inferences about species diversity. Challenges derive from the few phylogenetically informative characters of shells, insufficient information provided in original descriptions and sampling artefacts, which at the molecular level in spatially fragmented organisms can blur distinctions between genetically divergent populations and separate species. Based on a comprehensive dataset combining molecular, morphological and distributional data, this study identified several cases of shell-morphological plasticity and convergence. Results also suggest that what was thought to be a set of distinct, range-restricted species corresponds instead to a smaller number of more widespread species. Overall, using an appropriate sampling design, including type localities, allowed us to assign available names to evolutionarily significant units.
\end{abstract}

Keywords. Turbinidae, cox1, 28S, deep-sea environments, molecular systematics.

Castelin M., Williams S.T., Buge B., Maestrati P., Lambourdière J., Ozawa T., Utge J., Couloux A., Alf A. \& Samadi S. Untangling species identity in gastropods with polymorphic shells in the genus Bolma (Mollusca, Vetigastropoda). European Journal of Taxonomy 288: 1-21. http://dx.doi.org/10.5852/ejt.2017.288

\title{
Introduction
}

While soft-tissue anatomy is used for classification and recognition of higher taxonomic ranks in Mollusca, shell features are generally considered adequate and more convenient for species identification (Bouchet \& Strong 2010). One of the main reasons why the use of shell features is so emphasized in classical taxonomic treatments is that empty shells, i.e., the post-mortem remains of living animals, supplement live records for comprehensively documenting the geographical distribution and intraspecific variability of species. As a consequence, museum holdings, including type specimens used as concrete references for species names, mainly consist of empty shells (Bouchet \& Strong 2010). Hence, since the late $20^{\text {th }}$ century polymorphism of mollusc shells has been increasingly documented as a cause of taxonomic confusion (Knowlton 2000). Indeed, it is not uncommon that nominal species, delimited mainly or entirely by shell morphology, do not match genetic entities defined using neutral markers.

Discordances between morphospecies and genetic entities not only include cases of shell polymorphism within genetic entities, but also shell conservatism among distinct genetic entities. Such discordances were discussed in recent papers, for example in the genus Nacella Schumacher, 1817 (González-Wevar et al. 2011), the genus Bathytoma Harris \& Burrows, 1891 (Puillandre et al. 2010b) and the subfamily Rapaninae Gray, 1853 (Claremont et al. 2012). Alternatively, within a single nominal species analysis of neutral genetic markers can sometimes lead to the detection of both cryptic lineages and ecotypes (e.g., Lottia digitalis (Rathke, 1833); see Crummett \& Eernisse 2007). Polymorphism in shell characters may result from a recent adaptive radiation that can not yet be detected with neutral genetic characters and/or may be due to developmental plasticity in different environments (as, for example, in Vrijenhoek 2009). Similarity of shell features may result from parallel evolutionary processes occurring within distinct lineages evolving under similar environmental constraints (e.g., Littorina Férussac, 1822; Johannesson et al. 2010), or from allopatric speciation and non-adaptive radiation for maintenance of similar shells among divergent taxa within a single genus (e.g., Lunella Röding, 1798; Williams et al. 2011). These evolutionary processes include parallel divergent selection in reproductively isolated populations and 
also the persistence of ancestral polymorphism among closely related species. Taking into account these data, species delimitation in molluscs should not be solely based on shell features but on the integration of complementary sources of data, as discussed in Dayrat (2005) under the umbrella term of 'integrative taxonomy'. Such an integrative approach to species delimitation is in accordance with a unified view of the species concept (de Queiroz \& Weins 2007; Barberousse \& Samadi 2010). Moreover, in taxa for which knowledge about the determinism of shell variation is lacking, or for which data provide evidence of phenotypic plasticity, the morphology of the shells should not be used as primary evidence but as secondary evidence. This approach has recently been successfully applied, for example, in Weigand et al. (2011) and formalized in Puillandre et al. (2012). The variability of shell features may then be interpreted within these species hypotheses to determine diagnostic shell characters, which in turn may be used on post-mortem remains to complement knowledge about species distributions (as for example applied in Castelin et al. 2010, 2012).

The deep-sea gastropod turbinid genus Bolma Risso, 1826 is one example of a challenging case for taxonomic treatment at the species level. Specimens attributed to this genus occur at tropical and warm-temperate latitudes (in the Mediterranean, West African, South African, and Indo-West Pacific biogeographic provinces), mostly on hard bottoms at depths between 100 and 500-800 m (Alf et al. 2010), which make them difficult to sample. Nominal species display a wide range of shell morphologies, colours and sizes, but no consensus exists among taxonomists about which shell-character traits and which criteria must be evaluated to delineate species hypotheses objectively and operationally. For instance, geographical isolation has often been emphasized as a good proxy for species delimitation (see Alf et al. 2010). The rationale underlining this criterion is the bentho-pelagic life cycle (sensu SalviniPlawen \& Haszprunar 1987) of the superorder Vetigastropoda, to which the genus belongs. Indeed, in Vetigastropoda the larval development involves three planktonic stages (egg, trochophore and veliger), each poorly supplied with maternal resources, which limits the planktonic larval duration from several hours to a week (Salvini-Plawen \& Haszprunar 1987). Given these life-history traits, dispersal is expected to be limited among populations separated by hundreds of kilometers. Moreover, in Bolma most species descriptions are based on only a few individuals collected from one or only a few locations (e.g., Beu \& Ponder 1979). Thus, one of the main impediments to the taxonomic treatment of Bolma is the lack of documentation of individuals living outside of the type locality. As a consequence, intraspecific shell polymorphism across a species range is only rarely illustrated.

In this context, during the last forty years a suite of oceanographic expeditions organized within the framework of the Tropical Deep-Sea Benthos program (Bouchet et al. 2008) sampled the deep-sea benthos of the Indo-West Pacific and provided a large amount of appropriately preserved material that we took advantage of to clarify Bolma's taxonomy. The sampled specimens displayed a wider range of shell variability than previously documented (e.g., compared with that described in Beu \& Ponder 1979), suggesting either a higher level of intraspecific shell polymorphism than previously recognized or the presence of several species potentially new to science (cf. the most recently described species by Alf \& Kreipl 2011). The issues raised at the species level also arise at the genus level. Indeed, in recent phylogenetic results Bolma do not constitute a monophyletic lineage (Williams 2007). The genera Astraea Röding, 1798, Bellastraea Iredale, 1924, and Guildfordia Gray, 1850, which cluster with Bolma in the same clade, also present a wide variety of shell morphologies. The single valid species of Astraea is restricted to deep waters off New Zealand, the three valid species of Bellastraea are restricted to Southern Australia and the ten valid species of Guildfordia are restricted to the northwestern Pacific area.

In this study, we developed an integrative approach that follows the formalized approach to taxonomy proposed in Puillandre et al. (2012b), in which species hypotheses are primarily built on molecular character sets rather than on shell characters. We used DNA sequences from cox1 and 28S to build a molecular phylogeny of the genus Bolma integrating all of the available molecular data from the "deep- 
water" clade of the subfamily Turbininae (Williams 2007, i.e., the genera Astraea, Bellastraea, Guildfordia and Bolma). The diagnostic value of shell traits was then evaluated in the context of molecular results. First, we analyzed the shell variation within species hypotheses to assess the significance of the shell polymorphism among spatially isolated but genetically connected populations. Next, we examined shell variation among species hypotheses in relation to their phylogenetic relatedness. Last, using the shell characters determined as diagnostic of the species as defined with our integrative taxonomic treatment, scientific species names were attributed to the identified species hypotheses after comparing specimens in this study with type specimens deposited in museum collections or other available taxonomic data (e.g., original description, revision or type localities).

The results presented here showed that in Bolma, both traditional and molecular taxonomic treatments are associated with a number of challenges and pitfalls that can lead to poor inferences about species diversity. The main limitations derive from the poor evolutionary significance of the shell shape, the insufficient information provided in the original descriptions (notably about shell variability across the species range), and sampling artefacts, which at the molecular level in spatially fragmented organisms can blur distinctions between genetically divergent populations and distinct species. Based on both an integrative taxonomic approach rooted in a multi-locus phylogenetic framework and a large collection of over two hundred specimens sampled in deep-sea areas covering almost 160 degrees of longitude (from the Atlantic eastward to the Southwest Indian Ocean and the Southwest Pacific), the present study produced a comprehensive dataset combining molecular, morphological and distribution data for 22 putative species that can be used in future studies to address a wide variety of eco-evolutionary questions in tropical deep-sea ecology.

\section{Material and methods}

\section{Specimen sampling}

Most of the samples studied were collected during expeditions conducted by the Muséum national d'Histoire naturelle in Paris (MNHN), in partnership with the Institut de Recherche pour le Développement (IRD), Pro-Natura International (PNI), the Instituto Español de Oceanografia (IOE), the Natural History Museum of London (NHM) or Nagoya University (and donated to the NHM). Additional new samples were obtained from field contacts (see Acknowledgements). Samples include 196 specimens initially attributed to Bolma or Guildfordia collected throughout the Northwest and the Southwest Pacific Ocean (161 specimens), the Southwest Indian Ocean (32 specimens), the Eastern Atlantic ( 2 specimens) and the Mediterranean Sea (1 specimen) (Fig. 1). Overall, about 80 discrete sites were sampled by scuba diving, dredging and trawling at depths between 20 and $1000 \mathrm{~m}$ (Supplementary file). In the field, living specimens were anesthetized using magnesium chloride $\left(\mathrm{MgCl}_{2}\right)$ and a piece of tissue was cut from the head-foot and fixed in $95 \%$ ethanol. Shells were kept intact for identification. Vouchers were deposited in museum collections, primarily MNHN (see Table 1 and the Supplementary file).

\section{Molecular methods}

Total genomic DNA was extracted from the head-foot using the semi-automated ABI PRISM ${ }^{\mathrm{TM}} 6100$ Nucleic Acid PrepStation. The standard barcode region of the mitochondrial cox 1 gene, and a fragment of the nuclear 28S rRNA gene including the D1 and D2 domains (Hassouna et al. 1984; Palumbi et al. 1991) were amplified using the primers LCO1490 and HCO2198 (Folmer et al. 1994) and C1 and D2 (Jovelin \& Justine 2001), respectively. Polymerase chain reaction (PCR) protocols are described in Castelin et al. (2010). The annealing temperatures of the analyzed genes were $48^{\circ} \mathrm{C}$ for cox 1 and $52^{\circ} \mathrm{C}$ for $28 \mathrm{~S}$. PCR products were purified using Exonuclease I and Shrimp Alkaline Phosphatase, and sequenced with PCR primers using the BigDye Terminator v. 3.1 kit (Applied Biosystem) and run on an AB3730XL sequencer. All genes were sequenced in both directions and sequences were aligned using MUSCLE (Edgar 2004). Unique cox1 sequences were identified using DnaSP v. 5 (Librado \& Rozas 
2009) and multiple copies were removed from the full dataset in order to produce a subset including only unique sequences. All new sequences were deposited in GenBank and the BOLD System in the MARBOL project DS-BOLMA (Supplementary file).

\section{Additional data}

Published sequences for 19 specimens attributed to Bolma, Guildfordia and two other closely related genera, Astraea and Bellastraea, were also included in the dataset (Supplementary file). Following previous phylogenetic studies of Turbininae (Williams \& Ozawa 2006; Williams 2007), published sequences attributed to Cookia sulcata (Lightfoot, 1786) (one specimen), Astralium haematragum (Menke, 1829) (one specimen) and Prisogaster niger (W. Wood, 1828) (two specimens), were used as outgroup taxa (Supplementary file).

\section{From integrative taxonomy to naming species}

The processes of delimiting and identifying candidate species relied on a four-step integrative taxonomy approach in which species hypotheses are first based on molecular characters. These four steps, as detailed further in this section, were to: (1) derive primary species hypotheses (PSHs) based on the phylogenetic analysis using cox1; (2) document this set of PSHs for an unlinked nuclear marker based on a phylogenetic analysis and a visual inspection of the alignment for diagnostic sites among PSHs; (3) derive secondary species hypotheses (SSHs) by assessing the morphological variation of the shells within and among the PSHs and the geographical isolation among the PSHs; (4) assign a valid species name by comparing sequenced specimens with type specimens or other available taxonomic data (e.g., original description, revision or type localities).

For the first step, the cox1 dataset was analysed using the single and the multiple thresholds, General Mixed Yule Coalescent (GMYC) method (Pons et al. 2006). The GMYC method was run on both the cox1 dataset including all sequences and a reduced dataset including only unique sequences. Using JModeltest 2 (Guindon \& Gascuel 2003; Darriba et al. 2012), the best nucleotide substitution model

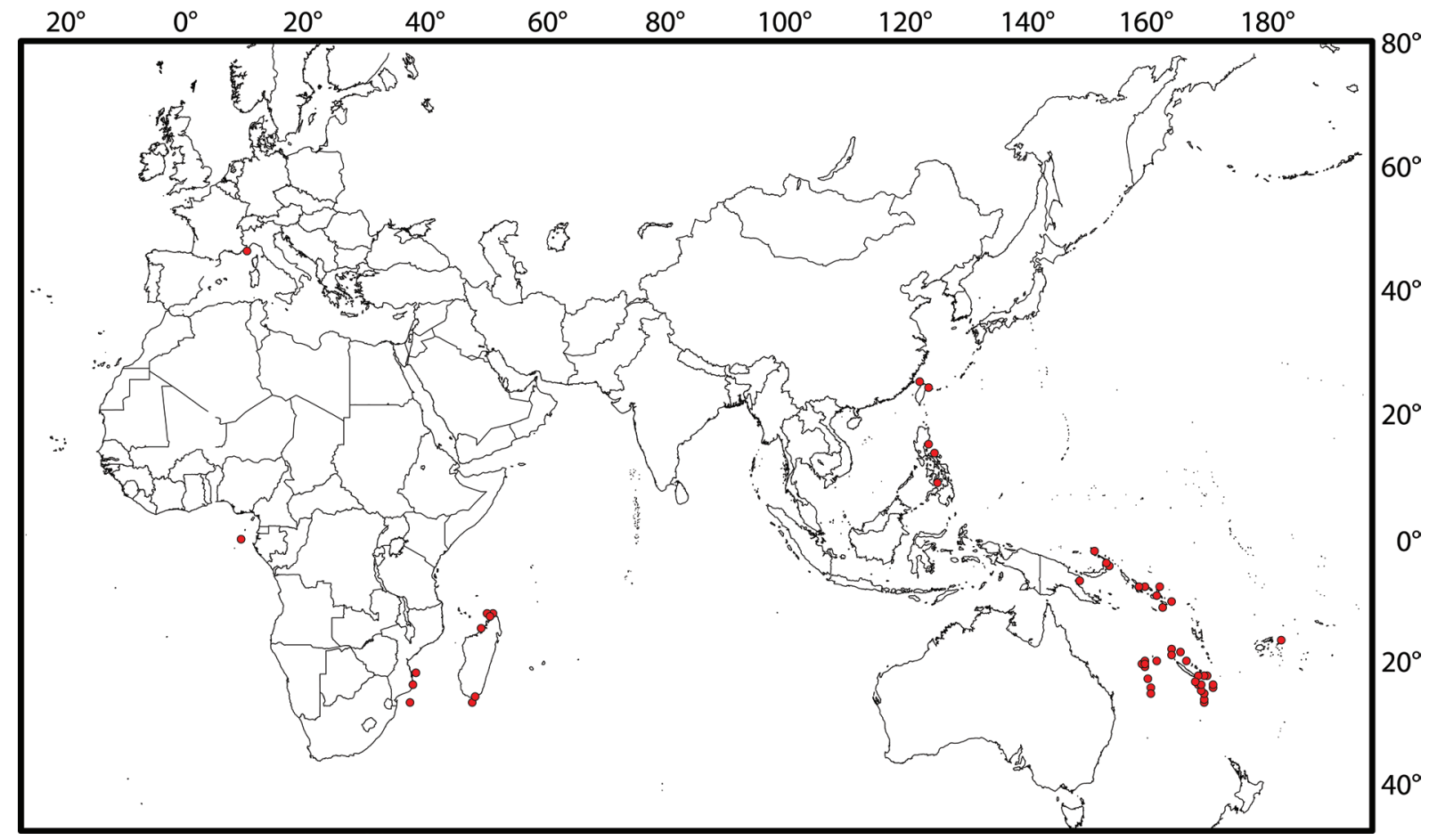

Fig. 1. Map showing sampling localities. See Supplementary file for details. 


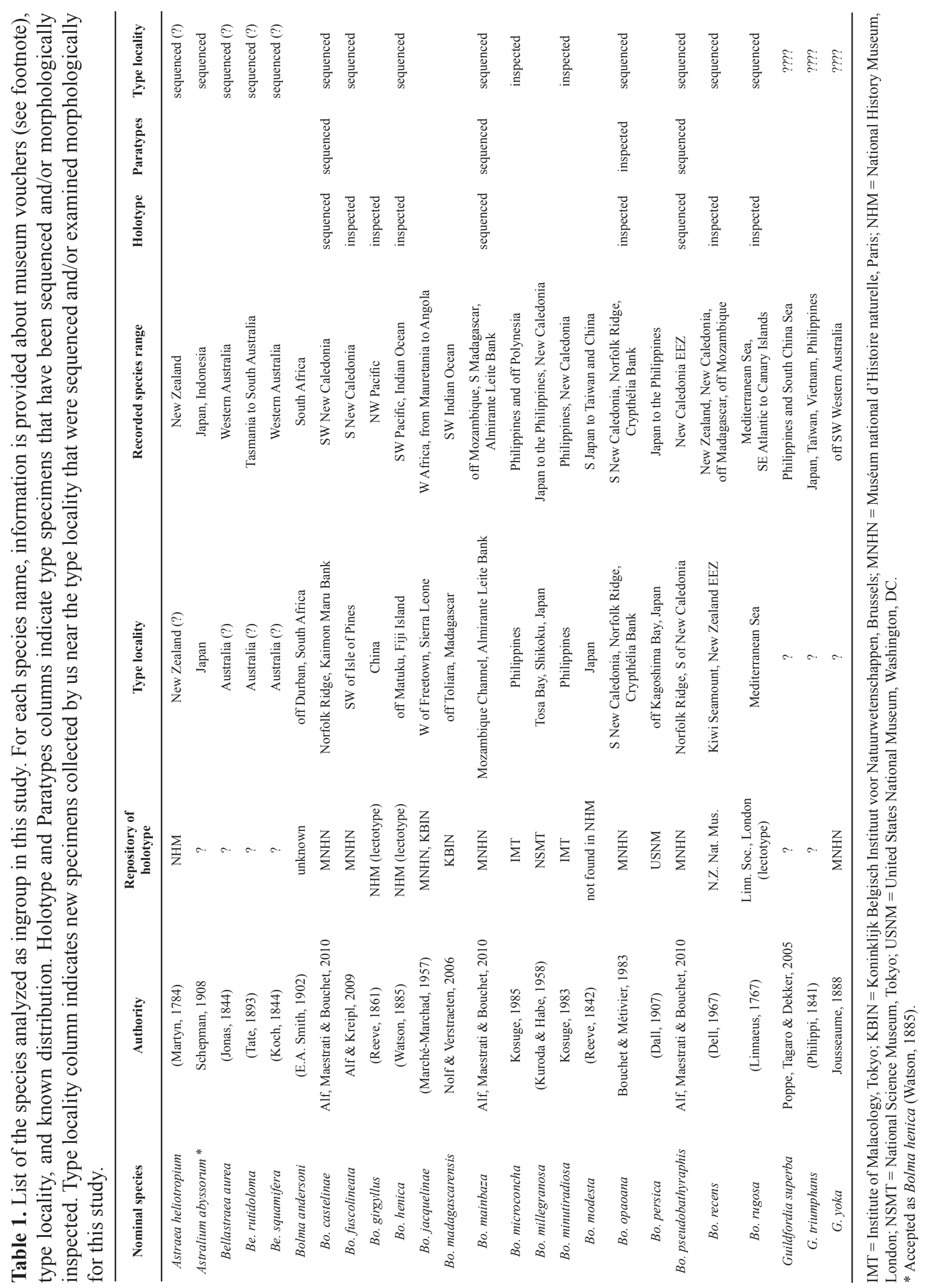


for both cox 1 datasets was determined to be Tamura-Nei with gamma distribution $(\operatorname{TrN}+\mathrm{G})$ for the three codon partitions. A Bayesian ultrametric tree was produced using BEAST v. 1.7.4 (Drummond et al. 2012) and a coalescent model of constant population size as the tree prior and heterogeneity of the mutation rate across lineages set under an uncorrelated log-normal clock. The mutation rate was set to one to get branch lengths in units of substitutions per site. Two independent analyses, with UPGMA starting trees, were run over 100 million generations with a sample frequency of 1000 . After checking for adequate mixing and convergence of runs by confirming effective samples size (ESS) values for all parameters were $>200$ with Tracer v. 1.6 (Rambaut et al. 2014), ten million samples were discarded as a burn-in, the two runs were pooled together and re-sampled every 10000 steps and a maximum clade credibility tree was compiled using TreeAnnotator (default parameters). The resulting tree served as an input for the GMYC script, which was run from the R package (R Development Core Team 2012) using the Splits (Ezard et al. 2009) and Ape (Paradis et al. 2004) libraries. The partitioning was also examined at the lower confidence limits of the GMYC approach (i.e., lower solution within two log-likelihood units of the maximum likelihood, equivalent to 95\% confidence intervals; Edwards 1984; Monaghan et al. 2009). Uncorrected p-genetic distances within and among genetic entities defined from the GMYC analysis were estimated using the Mega 6 software (Tamura et al. 2013) so that values could be directly compared with the literature.

For the second step, we tried to obtain at least one $28 \mathrm{~S}$ sequence for each genetic entity recognized using cox1. Monophyly of the PSHs delineated using cox1 were evaluated based on Bayesian analyses (BA) produced using BEAST (Drummond \& Rambaut 2007). The best nucleotide substitution model for the 28S dataset was determined using JModeltest 2 (Guindon \& Gascuel 2003; Darriba et al. 2012) to be the Tamura-Nei nucleotide substitution model with a proportion of invariant sites $(\operatorname{TrN}+\mathrm{I})$. Four independent analyses were each run for 40 million generations with a sample frequency of 5000. After checking for adequate mixing and convergence of runs, four million samples were discarded as burn-in, the four runs were pooled together and re-sampled every 5000 steps and a maximum clade credibility tree was calculated.

In the third step, PSHs were compared across independent molecular markers (cox1 and 28S). When cox1 and 28S both suggested monophyly of PSHs, the hypothesis of distinct species was favored. When several PSHs shared the same set of 28S genotypes, two cases were evaluated: (1) when morphological and cox1 variation among PSHs were low over large spatial scales, the hypothesis of a single species was favored; (2) when morphological and cox1 variation among PSHs were high over small spatial scales, the hypothesis of several distinct species was favored. This step allowed the definition of a final list of secondary species hypotheses (SSHs) that needed to be named.

In the last step, all sequenced individuals were examined morphologically. First, we analyzed the shell variation within SSHs to assess the significance of the shell polymorphism among spatially isolated but genetically connected populations. Next, to detect morphological convergences, we examined shell variation among SSHs in relation to their phylogenetic relatedness. Last, specimens were compared with type specimens or other available taxonomic data (e.g., original description, revision or specimens from type localities), and focusing on the sequenced specimens collected from the type localities, we tentatively attributed names to molecular species hypotheses (Supplementary file).

\section{Phylogenetic inferences}

The cox 1 and $28 \mathrm{~S}$ datasets were used to reconstruct the evolutionary history of species defined using the integrative approach described above. We used the Species Tree Ancestral Reconstruction (*BEAST) method implemented in BEAST v. 1.7.4 (Heled \& Drummond 2010; Drummond et al. 2012). By modelling intraspecific polymorphism and incomplete lineage sorting using several individuals per species and two loci, this method aims to reduce the discrepancy between the gene trees and the species 
tree. All individuals for which both cox 1 and $28 \mathrm{~S}$ sequences were available were included in the analysis. Sequences were partitioned by genes and cox 1 was further partitioned by codon position. Substitution models were as used previously. The birth-death model of speciation with incomplete sampling (Stadler 2009) was used as the tree prior and the heterogeneity of the mutation rate across lineages was set under an uncorrelated, relaxed, log-normal clock. The mean mutation rate was set to one. Two independent analyses were each run for 50 million generations, sampling every 10000 generations. After checking for adequate mixing and convergence of runs with Tracer software, five million samples were discarded as burn-in, the two runs were pooled together and a maximum clade credibility tree was calculated based on 9000 trees using TreeAnnotator. The maximum clade credibility tree was extracted with median node heights.

\section{Results}

\section{Integrative taxonomy}

\section{Cox1 dataset}

For the cox 1 gene fragment, the ingroup included 196 sequences varying in length from 596 to $658 \mathrm{bp}$. After excluding sites with missing data, we found 112 haplotypes, displaying 251 variable base pairs, of which 228 were phylogenetically informative. Effective sample sizes (ESS) of BA were higher than 500 for all parameters indicating that posterior distributions were well explored.

The multiple-threshold version of GMYC led to a partition where almost each haplotype was considered as a different PSH (cf. Fujisawa \& Barraclough 2013). Therefore, only the results from the single threshold version are discussed here. No differences were found between the partitioning obtained using the full cox 1 dataset and the dataset including only unique sequences. Therefore, only the results obtained using the full cox 1 dataset are discussed. The single-threshold GMYC analysis showed that the likelihood of the null model (that all sequences belong to a single species) was significantly lower than the maximum likelihood of the GMYC model (1728 vs 1746; ratio: $\left.36.6, \mathrm{P}=5.4 \times 10^{-8}\right)$. The threshold time ( $\mathrm{T}$ ) from the branch tips at which the transition from coalescent to speciation branching patterns occurred was 0.006 substitutions per site, resulting in the delineation of 37 PSHs labelled PSH-1 to PSH-37. Among these 37 PSHs, 25 are monophyletic with high (posterior probability, $\mathrm{PP}>90 \%$ ) to low $(\mathrm{PP}<70 \%)$ support and 12 are singletons (Fig. 2). PSH-1 corresponded to the out-group Cookia sulcata

Fig. 2. [next page] Molecular based species delineation of the genus "Bolma". A. Ultrametric tree produced using BEAST based on cox1 sequences. B. PSHs derived from the GMYC model and labelled from 1 to 37. C. PSHs derived from the GMYC model using the lower limit of the equivalent of a $95 \%$ confidence interval, and labelled from A to ZD. D. SSHs drawn from congruency between cox1 and 28S. Boxes with a black outline indicate that the SSH was monophyletic in both cox 1 and $28 \mathrm{~S}$ trees. Boxes without a black outline highlight SSHs for which molecular data were either incomplete or non-informative. SSHs labelled from A to ZD (following step C) or with the species name when our sequences matched published data associated with the species names. E. PSHs derived from the Bayesian analysis based on $28 \mathrm{~S}$ sequences. F. Bayesian, non-ultrametric tree produced using BEAST based on $28 \mathrm{~S}$ sequences. G. Species names retained in the present study. For the SSH E-F-G-H, the name Bo. henica was retained; however, Bo. henica abyssorum, Bo. henica madagascarensis and $B o$. henica henica are represented as sub-species separated by white dotted lines. For both trees, nodal support values are posterior probabilities (PP), shown only for $\mathrm{PP}>50 \%$. Branches with $\mathrm{PP}<50 \%$ were collapsed. Red and green branches correspond to monophyletic species hypotheses. Colour coded boxes: red corresponds to cox1 PSHs supported by PP > 95\%; light red corresponds to cox1 PSH supported by $\mathrm{PP}<95 \%$; light grey corresponds to cox 1 and $28 \mathrm{~S}$ singletons; a grey cross represents missing data; green corresponds to $28 \mathrm{~S}$ species hypotheses supported by PP $>95 \%$; light grey corresponds to groups of genotypes displaying diagnostic $28 \mathrm{~S}$ sites. Specimen numbers are given in the Supplementary file. 
CASTELIN M. et al., Molecular systematics of the genus Bolma Risso, 1826

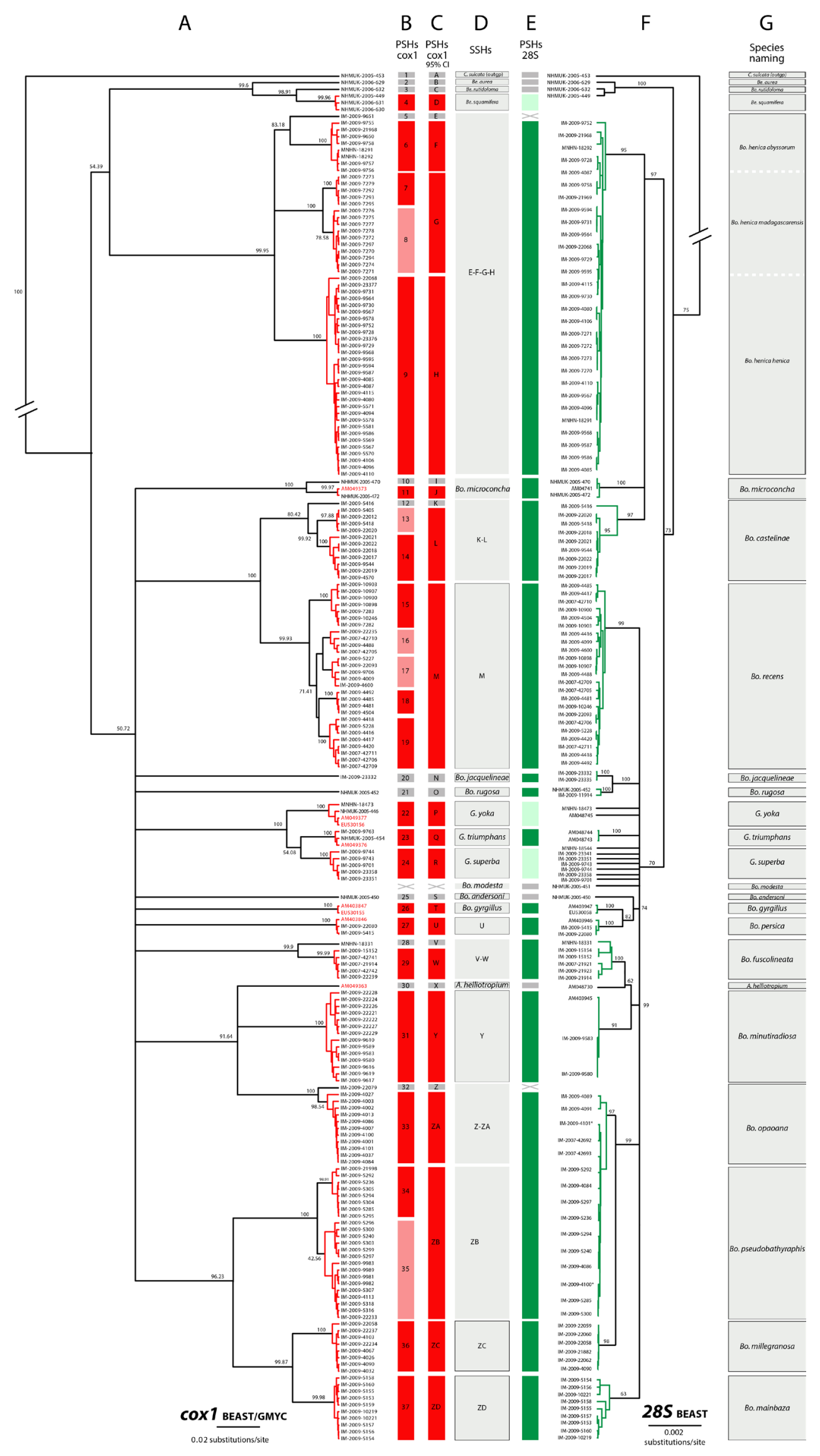


and PSH-2, PSH-3, PSH-4, PSHs 10-11, PSH-21, PSH-22, PSH-23, PHS-25, PSH-26 and PSH-30 corresponded respectively to published data associated with the species names Bellastraea aurea (Jonas, 1844), Be. rutidoloma (Tate, 1893), Be. kesteveni Iredale, 1924 (accepted as Be. squamifera (Koch, 1844)), Bolma microconcha Kosuge, 1985, Bo. rugosa (Linnaeus, 1767), Guildfordia yoka Jousseaume, 1899, G. triumphans (Philippi, 1841), Bo. andersoni (E.A. Smith, 1902), Bo. girgyllus (Reeve, 1861) and Astraea heliotropium (Martyn, 1784) (Supplementary file). Mean genetic distances within the 25 PSHs that were not singletons ranged from 0 to $2.4 \%$. Genetic distances among the $36 \mathrm{PSHs}$ of the ingroup ranged from 3 to $18 \%$. The total number of species hypotheses ranged from 30 to 43 based on model solutions at 2 log-likelihood units from the maximum, equivalent to $95 \%$ confidence intervals (CI). If the lower CI is used only 30 PSHs are defined (labelled PSH-A to PSH-ZD; Fig. 2 and the Supplementary file). In this partition PSH-G, PSH-L, PSH-M and PSH-ZB combined respectively with PSH-7 and PSH-8, PSH-13 and PSH-14, PSH-15 to PSH-19, and PSH-34 to PSH-35. Under this CI, the 18 monophyletic PSHs were supported by PP $>99 \%$. The mean genetic distances within each of the 18 PSHs that are not singletons ranged from 0 to $3.7 \%$ whereas mean genetic distances among the PSHs ranged from 3.8 to $18 \%$.

\section{S dataset}

The 28S gene fragment was successfully obtained for a subset of 129 individuals covering almost all genetic entities defined using the GMYC method (whichever threshold was used). Sequence lengths varied from 729 to $1452 \mathrm{bp}$. After excluding sites with missing data, the ingroup displayed 25 genotypes with 42 polymorphic sites, of which 32 were phylogenetically informative.

Including data available from GenBank, 28S sequences were obtained for 35 out of the 37 PSHs primarily defined using the GMYC method (Supplementary file). An additional published 28S sequence corresponding to a single specimen attributed to Bo. modesta (Reeve, 1843) was retained, although no cox1 data was available. Based on this dataset, PSHs 1 to 4 (C. sculata, Be. aurea, Be. rutidoloma and Be. squamifera), 22 (G. yoka), 24, 25 (Bo. andersoni), 30 (A. heliotropium) and Bo. modesta displayed diagnostic 28S sites (Fig. 2). Moreover, PSHs 20, 21, 23, 26 (Bo. girgyllus), 27 (Bo. persica), 31, 36 and 37 were recovered as monophyletic. Five closely related PSHs (PSHs 6-9 corresponding to PSH-F to PSH-H, 10-11 corresponding to PSH-I and PSH-J, 12-14 corresponding to PSH-K and PSH-L, 15-19 corresponding to PSH-M and 34-35 corresponding to PSH-ZB) shared the same set of polymorphic 28S sequences. Conversely, PSH-33 (corresponding to PSH-ZA) shared the same set of polymorphic 28S with the distant pair of PSHs 34-35 (corresponding to PSH-ZB) (Fig. 2).

\section{Secondary Species Hypotheses (SSHs)}

At this stage, the ingroup included 16 PSHs supported by a congruency between the cox 1 and the $28 \mathrm{~S}$ datasets (either using a monophyly or a similarity criterion, i.e., by checking for sites in the $28 \mathrm{~S}$ alignment that were diagnostic of PSHs) and thus retained as SSHs: Be. aurea, Be. rutidoloma, Be. squamifera, PSH-M, PSH-N, Bo. rugosa, G. yoka, G. triumphans, PSH-R, Bo. andersoni, Bo. girgyllus, PSH-U, A. heliotropium, PSH-Y, PSH-ZC and PSH-ZD (Fig. 2). Thirteen species hypotheses needed further examination, as molecular data at $28 \mathrm{~S}$ were either incomplete (i.e., absence of $28 \mathrm{~S}$ data) or noninformative (i.e., lack of diagnostic $28 \mathrm{~S}$ sites among PSHs). For two groups of PSHs (PSHs E-F-G-H and PSHs Z-ZA-ZB), 28S sequences were shared among PSHs. In the first group (PSHs E-F-G-H), the PSHs were separated by genetic distances lower than $9.1 \%$ and corresponded to distinct biogeographic areas that are very isolated from one another (Northwest Pacific, Madagascar and Southwest Pacific, respectively). The hypothesis of a single SSHs was thus favored. In the second group (PSHs Z-ZAZB), the PSHs were separated by genetic distances higher than $13.2 \%$ and corresponded to specimens sampled in the same biogeographic area (New Caledonia EEZ). The hypothesis of distinct SSHs was thus favored. Next, in each of the four pairs of PSHs E-F, I-J, K-L, V-W and Z-ZA, one PSH corresponded to a 
singleton that did not correspond to any clear pattern in geographic or depth distribution (Supplementary file). Based on shell morphology, they were classified as five species hypotheses, which led our dataset to 22 putative species in total.

\section{Attribution of species names and shell variation}

Shell variation within and among putative species was assessed before assigning species names. However, for the sake of clarity, we present the attributions of species names along with their shell variation.

Among the 22 final species hypotheses, 10 clustered with sequences published in GenBank with the corresponding names Be. aurea, Be. rutidoloma, Be. squamifera, Bo. microconcha, Bo. rugosa, G. yoka, G. triumphans, Bo. andersoni, Bo. girgyllus and A. heliotropium. Among the 22 final species hypotheses, 7 included specimens collected near or at the type locality (Bo. henica (Watson, 1885), cluster of PSHs E-H; Bo. recens (Dell, 1967), PSH-M; Bo. jacquelineae (Marche-Marchad, 1957), PSH-N; G. superba Poppe, Tagaro \& Dekker, 2005, PSH-R; Bo. persica (Dall, 1907), PSH-U; Bo. fuscolineata Alf \& Kreipl, 2009, PSHs V-W; Bo. opaoana Bouchet \& Métivier, 1983, PSHs Z-ZA).

The SSHs corresponding to the cluster of PSH-E, PSH-F, PSH-G and PSH-H included specimens sampled near the type localities of three species names (respectively, Astralium abyssorum Schepman, 1908 (currently accepted as Bo. henica) (PSH-E, PSH-F), Bo. madagascarensis Nolf \& Verstraeten, 2006 (PSH-G) and Bo. henica (PSH-H)). The retained species name for that SSH was Bo. henica associated with three geographic subspecies (Bo. henica abyssorum, Bo. henica madagascarensis and Bo. henica henica). Specimens of PSH-H (Bo. henica henica; Fig. 3A, c) were morphologically very similar to the specimens of PSH-Y (Fig. 3A, d), although not closely related in either the cox1 or the 28S tree (Figs 2, 4). After close examination, subtle shell differences were observed among adult specimens of the two groups. Here, the attribution of the name Bo. cf. minutiradiosa Kosuge, 1983 to PSH-Y was based on the shell morphology, by comparing the individuals of PSH-Y to morphologically similar specimens available in the dry collections of the MNHN. In our samples Bo. henica henica has a broad geographic range, recorded from the Solomon Islands to the New Caledonia EEZ, whereas Bo. cf. minutiradiosa has a narrow geographic range, restricted to the south of New Caledonia Island, Lansdowne Bank and Kelso Bank on the Lord Howe seamount Ridge. The two species thus have a narrowly overlapping range, as they were both found on the Lansdowne Bank at depths between 427 and $550 \mathrm{~m}$ (Fig. 3A).

Among the 22 final species hypotheses, 3 SSHs (PSHs K-L, PSH-ZB and PSH-ZD) did not correspond to any of the names existing in the taxonomic literature, and they were thus described as new species (respectively, Bo. castelinae Alf, Maestrati \& Bouchet, 2010; Bo. pseudobathyraphis Alf, Maestrati \& Bouchet, 2010; Bo. mainbaza Alf, Maestrati \& Bouchet, 2010). Species descriptions were based on the molecular data presented here before their actual publication (see Alf et al. 2010).

Three species (Bo. recens, Bo. mainbaza and Bo. pseudobathyraphis) exhibited a wide range of morphological variations. In Bo. recens (Fig. 3B, a-d), the morphological partition was not fully consistent with the mitochondrial structure. Some morphologically distinct and geographically separate individuals shared the same mitochondrial cox 1 haplotype. Within both Bo. mainbaza (Fig 3C, a) and Bo. pseudobathyraphis (Fig 3C, b), two morphs were distinguished based on the presence/absence of spines and the presence of small brown spots. Within Bo. mainbaza, the two forms were found at the same localities and within the same range of depth. Within Bo. pseudobathyraphis, most individuals were very similar in shape, sculpture and size, except those from the southern seamounts of the Lord Howe Ridge (i.e., on the seamounts Nova, Kelso and Capel), where a morph with long spines was sampled. On these seamounts the spiny and non-spiny morphs co-occurred at the same localities and the same range of depths, and were not genetically distinct. 

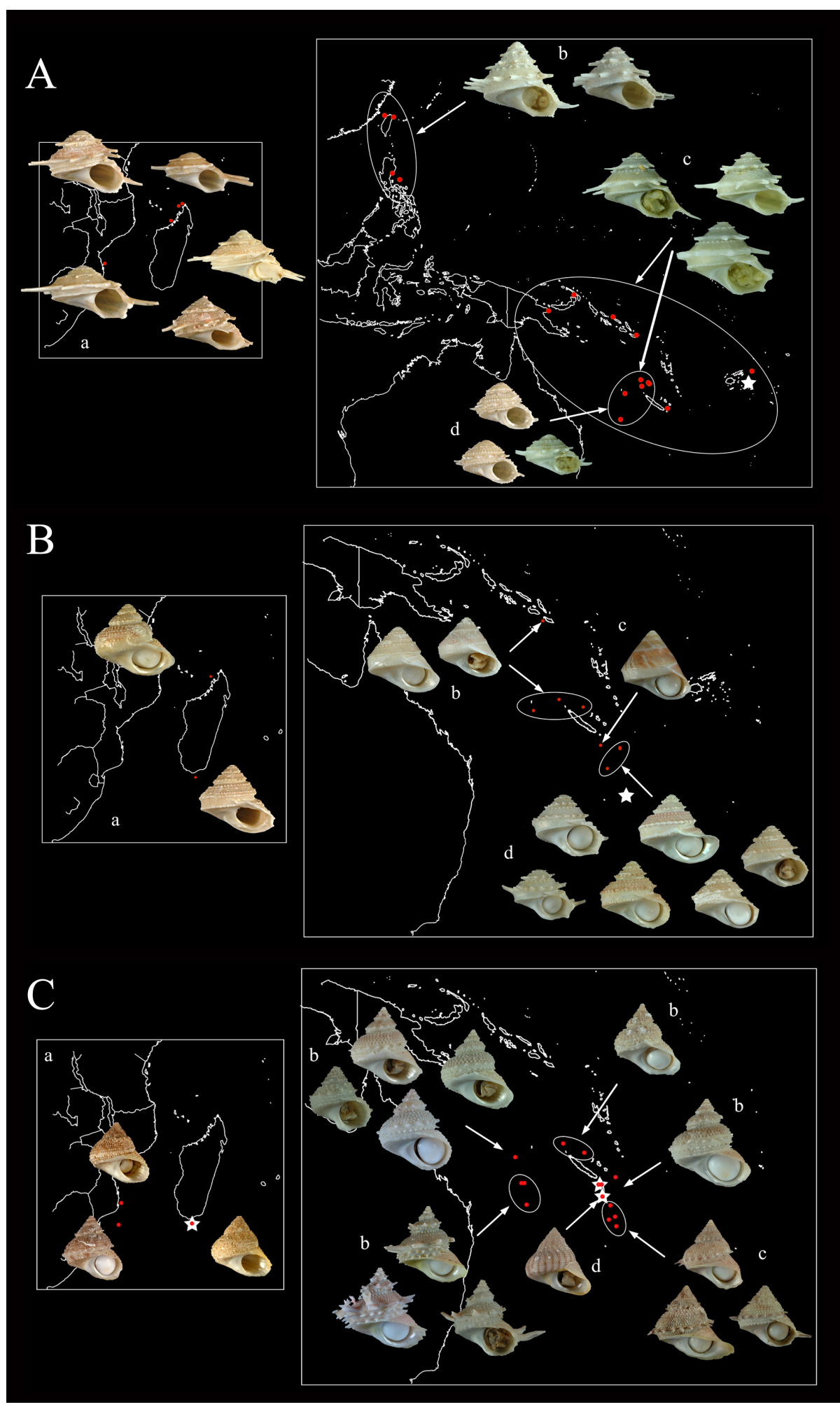

Fig. 3. A. a, Bolma henica madagascarensis (Indian Ocean); b, Bo. henica abyssorum; c, Bo. henica henica, with type locality represented by a white star (Fiji Island, Southwest Pacific); d, Bo. cf. minutiradiosa. B. a-d, distinct shell morphs found in Bo. recens, with type locality represented by a white star (Kiwi seamount, Three Kings Ridge). C. a, Bo. mainbaza, with type locality (South Madagascar); b, Bo. pseudobathyraphis, with type locality (South New Caledonia); c, Bo. millegranosa; d, Bo. opaoana with type locality (South New Caledonia, Crypthélia Bank). 
Fig. 4. Shell diversity across the molecular phylogeny of the "deep-water" clade of the subfamily Turbininae (Williams 2007, i.e., the genera Astraea, Bellastraea, Bolma and Guildfordia). The phylogeny is based on Bayesian analyses of the concatenated sequences from cox 1 and $28 \mathrm{~S}$ genes, incorporating an uncorrelated relaxed, lognormal clock produced using *BEAST. The tree is a maximum clade credibility tree with median node heights based in 9000 trees. Support values are posterior probabilities (PP); branches $<50 \%$ were collapsed. Species names are labelled on the right-hand side. Species hypotheses previously delineated by the integrative taxonomy approach are highlighted by the grey boxes. $\operatorname{cox} 1-28 \mathrm{~S} /{ }^{*} \mathrm{BEAST}$

0.07 substitutions/site

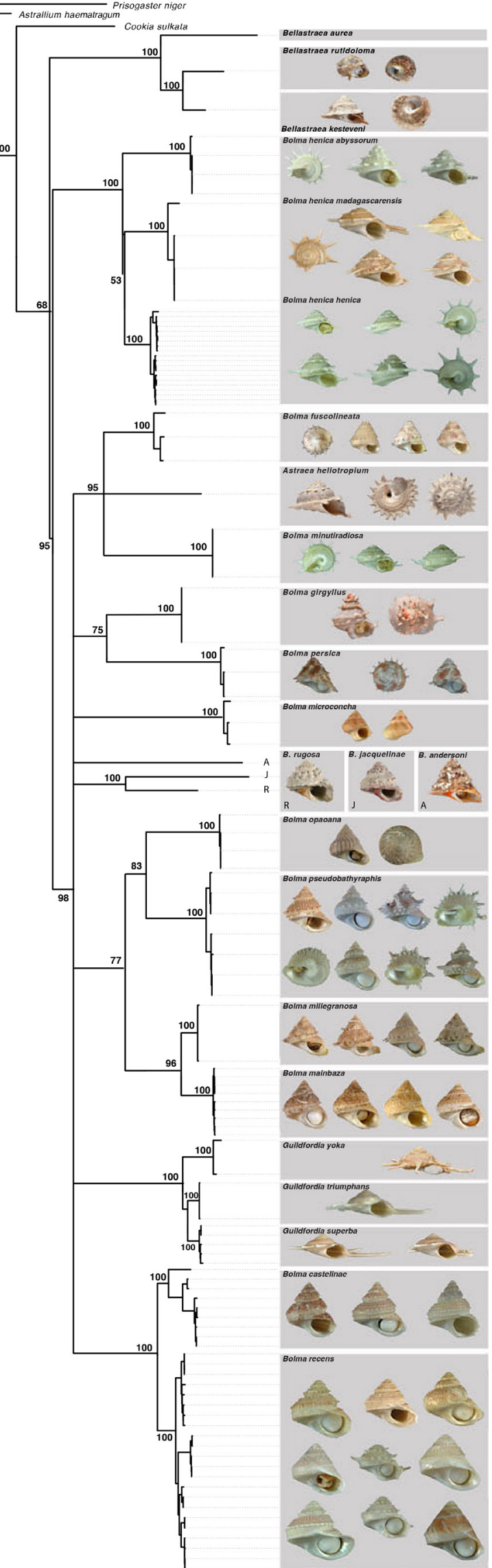


Considering this wide range of morphological variations, specimens of the spiny morph of $B o$. pseudobathyraphis were morphologically very similar to the specimens of PSH-ZC, which also bear spines (Fig. 3C, c). However, based on comparisons of shell morphology between our samples, photographs in the original description and available taxonomic revisions, the SSHs-ZC was assigned to Bo. millegranosa (Kuroda \& Habe in Habe, 1958).

\section{Phylogenetic inferences}

No incongruence was detected between the single-gene analyses (cox1 and 28S datasets). However, phylogenetic relationships were generally poorly resolved, with only a few well-supported clades (cf. Fig. 2). The topologies inferred from single-gene analyses were consistent with the topology obtained from the species tree using combined sequences. Analyses of the combined dataset supported the monophyly of the ingroup consisting of species of Astraea, Bellastraea, Bolma and Guildfordia ( $\mathrm{PP}=80 \%$, Fig. 4). Within this clade the analysis distinguished four highly supported clades (with PP $>99 \%$, Fig. 4): (i) the three species attributed to the genus Bellastraea, (ii) Bo. henica abyssorum, Bo. henica madagascarensis and Bo. henica henica, (iii) Bo. pseudobathyraphis, Bo. millegranosa and Bo. mainbaza, (iv) the three species attributed to the genus Guildfordia, Bo. castelinae and Bo. recens. The three following groups were distinguished, although poorly supported (with PP $<83 \%$, Fig. 4): (a) the group (iii) plus Bo. opaoana, Bo. rugosa, Bo. jacquelineae and Bo. andersoni $(\mathrm{PP}=83 \%)$, (b) Bo.fuscolineata, A. heliotropium and Bo. cf. minutiradiosa ( $\mathrm{PP}=75 \%$ ), (c) Bo. gyrgillus, Bo. persica and Bo. microconcha $(\mathrm{PP}<50 \%)$.

\section{Discussion}

\section{Molecular data as the primary source of information for exploring species hypotheses}

Using molecular, rather than morphological characters as primary sources of evidence enabled rapid, objective and effective production of species hypotheses. Unlike molecular data, shell morphology had a poor species-level taxonomic resolution, especially for polymorphic, cryptic and sibling species. In these cases, shell polymorphism was actually greater within species than among species and led to incorrect species hypotheses compared with those defined using molecular characters. For example, on New Caledonia seamounts two co-occurring morphs, corresponding to the presence/absence of spines, were assigned through traditional malacological methods, following the classification schemes of Beu \& Ponder (1979), to two separate species hypotheses: the "spine-bearing" Bo. millegranosa and the "spineless" Bo. bathyraphis (E. A. Smith, 1899). Molecular data revealed an entirely different partitioning scheme, with a polymorphic species hypothesis including both "spine-bearing" and "spineless" forms (Bo. pseudobathyraphis; Alf et al. 2010), and a morphologically more homogeneous species hypothesis containing only the "spine-bearing" forms (Bo. millegranosa) (Fig. 3C, c). In this particular case, similarities of the general shell shape between these closely related species (or the retention of a plesiomorphic similarity), combined with the non-obligatory presence of spines within one of the two species caused considerable taxonomic confusion. Marine gastropod species often change shell morphologies under different environmental and biological conditions, primarily for protection from the environment and/or predators. In the shallow-water turbinid Turbo cornutus Lightfoot, 1786, different degrees of seashore wave exposure have been shown to influence spine lengths (Ino 1953; Kurihara et al. 2006). Our study showed other cases of intraspecific shell polymorphism, for instance within Bo. henica henica and Bo. recens, thus emphasizing the difficulty in estimating species diversity in this genus. We also showed that the presence or absence of spines can occur within a single environment.

Our data also revealed crypticism between species that are not sister species (herein assigned to Bo. henica henica (Fig. 3A, c) and Bo. cf. minutiradiosa (Fig. 3A, d), but both traditionally recognized as Bo. henica). Despite exhibiting similar morphology and ecology (co-occurrence on the Lansdowne Bank in the New Caledonia EEZ), the multi-locus phylogeny provided evidence that the two species 
are distantly related species within Bolma. These findings are consistent with the hypothesis that their morphological similarity may be a result of local adaptation to similar environments. Convergent evolution of shell-shape among phylogenetically divergent species experiencing similar environmental selection pressures has been widely documented (even though not always formally tested) in molluscs, including the freshwater limpets of the African genus Burnupia (Albrecht et al. 2004), freshwater snails inhabiting geothermal springs in Oregon (Physa Draparnaud, 1801; Moore et al. 2015), the hydrothermal vent snails Alviniconcha Okutani \& Ohta, 1988 (Johnson et al. 2015) and the bathyal gastropod genus Gemmuloborsonia Shuto, 1989 (Puillandre et al. 2010a). Along with these examples, our study suggested that shell shape in Bolma is highly adaptive and therefore has poor species-level significance. Overall, this reinforces the idea that in shelled molluscs, shell shape cannot be used as a primary proxy for assessing species hypotheses and that, where possible, molecular characters should be used to assess species hypotheses.

\section{Geography is also a bad proxy for species delineation}

Most of the analyzed species were geographically restricted to either a single site, a single marine ecoregion or a single province (sensu Spalding et al. 2007) despite widespread sampling. This reinforces the general assumption that because of their lecithotrophic mode of larval development, Bolma species mostly have restricted distribution ranges. However, the presence in our samples of a minority of surprisingly widespread species (extending from the Western Indian Ocean to the Southwest IndoPacific) suggests that a range-restricted pattern cannot be generalized within Bolma and that some processes may have enabled certain species to gain a wider geographic range than others. In shallowwater habitats, numerous studies have shown that a positive relationship between dispersal ability and geographical range size is not a general rule for marine organisms (Lester et al. 2007). Species range size is influenced by various factors, including variability in physiological and ecological tolerances or large-scale changes in resource and habitat availability (e.g., Brown 1984; Gaston et al. 2003). Though such factors could not be evaluated here, they may also influence the distribution of deep-sea organisms (Castelin et al. 2010, 2012). In a taxonomic context, this suggests that geographic isolation, even when suspected from expected dispersal abilities, should not be used as a proxy for delineating species. Indeed, the integrative framework applied here indicated that what was thought to be a set of distinct, range-restricted species (Bo. henica henica, Bo. henica madagascarensis, Bo. henica abyssorum, $B o$. recens recens and Bo. recens clemenceae) corresponds to a smaller number of more widespread species (Bo. henica and Bo. recens). This is a rare contrary example of taxonomic inflation, where multiple nominal species are synonymized thanks to the molecular taxonomic approach (Isaac et al. 2004). Similarly, future integrative taxonomic efforts may show that some species of Bolma, currently described as rare and spatially restricted to a single isolated site, such as for example the French Polynesian Bo. tantalea Alf, Maestrati \& Bouchet, 2010, may have a larger geographic distribution than initially thought. Indeed, although no mitochondrial data are available, our nuclear data (not included in this study) did not support the genealogical independence of that species from the widespread $B o$. recens.

\section{Assigning scientific names using DNA and type localities}

Using an appropriate sampling design, including as many type localities as possible and as many species as possible, was fundamental to assigning existing species names to evolutionarily significant units. Until recently, species descriptions were based on few specimens collected from very restricted locations. As a consequence, the extent of the distribution ranges of these species, and most importantly, the geographic variation of shell polymorphism outside of the type locality, were usually not documented. In this study, as we observed species with both a high level of shell diversity and a wide geographic distribution, and the incompleteness of old taxonomic data challenged linking newly sampled species to existing names. In this context, only species that were characterized by obvious shell characters (Bo. opaoana), or that 
included specimens collected at the type locality (B. recens, Bo. henica henica) could be attributed to a name with confidence. Alternatively, and when none of the existing descriptions could be confidently assigned to delineated species, new species were described (Bo. mainbaza, Bo. pseudobathyraphis, Bo. castelinae; Alf et al. 2010). This approach was more difficult to apply when several cryptic species occurred at the same locality (Bo. henica henica, Bo. cf. minutirasiosa), but only a single name (here, Bo. henica henica) was a priori available for that area and that morph. In these cases, a more critical examination of specimens to look for diagnostic shell characters enabling the distinction of cryptic species, combined with the examination of dry shells collected from other locations in the Indo-Pacific, allowed us to propose species names (Bo. henica henica, type locality: Fiji; Bo. minutiradiosa, type locality: Balut Island, Bohol Sea, Philippines), which will need to be validated with further sequencing of specimens of Bo. minutiradiosa collected near the type locality.

\section{Undersampled, spatially fragmented organisms may challenge GMYC accuracy}

Our results suggested that within species, high levels of genetic differentiation at cox1, combined with a small sample size, could prevent the GMYC model from distinguishing the break between coalescent and speciation branching rate. Most of the analyzed species showed high levels of intraspecific genetic differentiation at cox1, and in five cases (Bo. microconcha, Bo. castelinae, Bo. recens, Bo. fuscolineata and Bo. pseudobathyraphis), GMYC overestimated species richness. However, when the sample size was high (as in Bo. recens and Bo. pseudobathyraphis), the lower confidence limits identified these diverging PSHs as belonging to a single species. In every case, both the use of a second, independent molecular marker and the analysis of distribution patterns were critical for selecting the best set of PSHs produced by GMYC. Previous studies have shown the tendency for GMYC to over-split unresolved nodes that result from under-sampled species and/or strong intraspecific genetic structure (e.g., Fujisawa \& Barraclough 2013; Talavera et al. 2013; Zhang et al. 2013). In accordance with a previous study on the vetigastropod genus Lunella Röding, 1798 (Williams et al. 2011), our results showed that the lower confidence limits of the GMYC approach provided the best PSH set and may therefore be more appropriate, when sample size is sufficient, for distinguishing between intra- and interspecific genetic divergences in groups with low dispersal potential (or high intraspecific genetic structuring).

\section{Microhabitat partitioning}

Although it could not be evaluated formally, our data suggested microhabitat partitioning, which may indicate that species of Bolma are subject to strong local selection pressures. As mentioned above, most of the abundantly sampled species displayed strong genetic structuring. However, while Bo. castelinae, for example, showed genetic structuring congruent with geographical isolation of populations (e.g., Lord Howe Ridge vs Norfolk Ridge), Bo. recens, Bo. henica henica and Bo. pseudobathyraphis had very inconsistent genetic structuring, with nearby populations showing greater genetic differentiation than more distant ones. Similarly and independently, for these species the different morphs observed within species were not strictly clustered by geographic location (Fig. 3). Genetic responses to local selection pressures and ecotype-selective sweeps have been documented in seashore gastropods with restricted gene flow (e.g., Johannesson et al. 2010; Kemppainen et al. 2010; Ilves et al. 2010) and may explain some of these observations. The detection of genetic structuring in a mitochondrial marker that is incongruent with the spatial distribution of organisms, if not due to methodological or sampling artefact, could be a result of local adaptation to different microenvironments. Further studies might also investigate the hypothesis of selection favoring a beneficial mutation, resulting in hitchhiking of neutral mitochondrial markers.

\section{Conclusion}

Overall, this study showed that both the alpha taxonomy of molluses and the traditional criteria applied in species description (i.e., the use of dried material, shell-morphology, and a geographic isolation criterion) 
may lead to poor inferences about species diversity and constitute a barrier toward understanding and managing marine ecosystems. Modern species descriptions should be based on objective and robust species hypotheses established within a phylogenetic framework, and ideally including several specimens in order to reflect both species ranges and morphological polymorphism across these ranges. With the increased accessibility to high throughput DNA sequencing, future species descriptions should always include molecular data.

\section{Acknowledgments}

The molecular material in this paper originates from numerous deep sea cruises conducted by MNHN and the Institut de Recherche pour le Développement (IRD) as part of the "Tropical Deep-Sea Benthos" programme. The Philippines part of the programme was conducted jointly with the Philippines Bureau of Fisheries and Aquatic Research (BFAR) with the support of the Richard Lounsbery Foundation. The material from the SW Indian Ocean was collected as part of a cluster of Mozambique-Madagascar expeditions (2009-2010) under the "Our Planet Reviewed" programme conducted jointly by MNHN (PI: Philippe Bouchet) and Pro-Natura International (PNI) and funded by the Total Foundation, the Prince Albert II of Monaco Foundation and the Stavros Niarchos Foundation; partners included the Instituto Español de Oceanografia (IOE), the Institut d'Halieutique et des Sciences Marines, the University of Toliara, Madagascar (IH.SM) and the Madagascar bureau of the Wildlife Conservation Society (WCS). We are especially grateful to our colleagues Marie-Catherine Boisselier, Virginie Héros, Laure Corbari, Cyndie Dupoux, Julien Brisset, Eric Pante, Yuri Kantor and Pierre Lozouet for companionship at sea and access to crucial literature. All expeditions operated under the regulations then in force in the countries in question and satisfy the conditions set by the Nagoya Protocol for access to genetic resources. We also warmly thank José Rosado for providing material of Bolma jacquelinae. We thank all the partners that have financially supported this work: (1) the Consortium National de Recherche en Genomique; (2) the ANR grant "Bioneocal" (PI: Philippe Grandcolas); (3) the Service de Systématique Moléculaire (UMS2700 MNHN-CNRS); (4) the project "Macrophylogeny of Life" (PI: Guillaume Lecointre), part of agreement no. 2005/67 between the Genoscope and MNHN; (5) the ATM Barcode (PIs: Sarah Samadi and Jean-Noël Labat); and (6) the network "Bibliothèque du Vivant" (BdV) funded by MNHN, CNRS, INRA and the Centre National de Séquençage. Finally, we are grateful to Nicolas Puillandre for discussions and constructive comments on the manuscript.

\section{References}

Albrecht C., Wilke T., Kuhn K. \& Streit B. 2004. Convergent evolution of shell shape in freshwater limpets: the African genus Burnupia. Zoological Journal of the Linnean Society 140: 577-586. http:// dx.doi.org/10.1111/j.1096-3642.2003.00108.x

Alf A. \& Kreipl K. 2011. The family Turbinidae. Subfamilies Turbininae Rafinesque, 1815 and Prisogasterinae Hickman \& McLean, 1990. In: Poppe G.T. \& Groh K. (eds) A Conchological Iconography: 1-82. Conchbooks, Hackenheim, Germany.

Alf A., Maestrati P. \& Bouchet P. 2010. New species of Bolma (Gastropoda: Vetigastropoda: Turbinidae) from the tropical deep sea. The Nautilus 124: 93-99.

Barberousse A. \& Samadi S. 2010. Species from Darwin onward. Integrative Zoology 5: 187-197. http://dx.doi.org/10.1111/j.1749-4877.2010.00204.x

Beu A.G. \& Ponder W.F. 1979. A revision of the species of Bolma Risso, 1826 (Gastropoda: Turbinidae). Records of the Australian Museum 32: 1-68. http://dx.doi.org/10.3853/j.0067-1975.32.1979.201

Bouchet P., Héros V., Lozouet P. \& Maestrati P. 2008. A quarter-century of deep-sea malacological exploration in the South and West Pacific: Where do we stand? How far to go? In: Héros V., Cowie R.H. \& 
Bouchet P. (eds) Tropical Deep-Sea Benthos 25: 9-40. Mémoires du Muséum national d'Histoire naturelle 196. Muséum national d'Histoire naturelle, Paris.

Bouchet P. \& Strong E. 2010. Historical name-bearing types in marine molluscs: an impediment to biodiversity studies? Systema Naturae 250: 63-74.

Brown J.H. 1984. On the relationship between abundance and distribution of species. American Naturalist 124: 255-279.

Castelin M., Lambourdiere J., Boisselier M.-C., Lozouet P., Couloux A., Cruaud C. \& Samadi S. 2010. Hidden diversity and endemism on seamounts: focus on poorly dispersive neogastropods. Biological Journal of the Linnean Society 100: 420-438. http://dx.doi.org/10.1111/j.1095-8312.2010.01424.x

Castelin M., Lorion J., Brisset J., Cruaud C., Maestrati P., Utge J. \& Samadi S. 2012. Speciation patterns in gastropods with long-lived larvae from deep-sea seamounts. Molecular Ecology 21: 4828-4853. http://dx.doi.org/10.1111/j.1365-294X.2012.05743.x

Claremont M., Vermeij G.J., Williams S.T. \& Reid D.G. 2012. Global phylogeny and new classification of the Rapaninae (Gastropoda: Muricidae), dominant molluscan predators on tropical rocky seashores. Molecular Phylogenetics and Evolution 66: 91-102. http://dx.doi.org/10.1016/j.ympev.2012.09.014

Crummett L.T. \& Eernisse D.J. 2007. Genetic evidence for the cryptic species pair, Lottia digitalis and Lottia austrodigitalis and microhabitat partitioning in sympatry. Marine Biology 152: 1-13. http:// dx.doi.org/10.1007/s00227-007-0621-4

Darriba D., Taboada G.L., Doallo R. \& Posada D. 2012. jModelTest 2: more models, new heuristics and parallel computing. Nature Methods 9: 772-772. http://dx.doi.org/10.1038/nmeth.2109

Dayrat B. 2005. Towards integrative taxonomy. Biological Journal of the Linnean Society 85: 407-415. http://dx.doi.org/10.1111/j.1095-8312.2005.00503.x

de Queiroz K. \& Weins J. 2007. Species concepts and species delimitation. Systematic Biology 56: 879-886. http://dx.doi.org/10.1080/10635150701701083

Drummond A.J. \& Rambaut A. 2007. BEAST: Bayesian evolutionary analysis by sampling trees. BMC Evolutionary Biology 7: e214. http://dx.doi.org/10.1186/1471-2148-7-214

Drummond A.J., Suchard M.A., Xie D. \& Rambaut A. 2012. Bayesian phylogenetics with BEAUti and the BEAST 1.7. Molecular Biology and Evolution 29: 1969-1973. http://dx.doi.org/10.1093/molbev/ $\underline{\operatorname{mss} 075}$

Edgar R.C. 2004. MUSCLE: multiple sequence alignment with high accuracy and high throughput. Nucleic Acids Research 32: 1792-1794. http://dx.doi.org/10.1093/nar/gkh340

Edwards A.W.F. 1984. Likelihood. John Hopkins University Press, London.

Ezard T., Fujisawa T. \& Barraclough T.G. 2009. SPecies LImits by Threshold Statistics. Available from https://r-forge.r-project.org/projects/splits/ [accessed 8 Feb. 2017].

Folmer O., Black M., Hoeh W., Lutz R. \& Vrijenhoek R. 1994. DNA primers for amplification of mitochondrial cytochrome c oxidase subunit I from diverse metazoan invertebrates. Molecular Marine Biology and Biotechnology 3: 294-299.

Fujisawa T. \& Barraclough T.G. 2013. Delimiting species using single-locus data and the Generalized Mixed Yule Coalescent (GMYC) approach: a revised method and evaluation on simulated datasets. Systematic Biology 62: 707-724. http://dx.doi.org/10.1093/sysbio/syt033

Gaston K.J., Jones A.G., Hanel C. \& Chown S.L. 2003. Rates of species introduction to a remote oceanic island. Proceedings of the Royal Society B 270: 1091-1098. http://dx.doi.org/10.1098/rspb.2003.2332 
González-Wevar C.A., Nakano T., Cañete J.I. \& Poulin E. 2011. Concerted genetic, morphological and ecological diversification in Nacella limpets in the Magellanic Province. Molecular Ecology 20: 1936-1951. http://dx.doi.org/10.1111/j.1365-294X.2011.05065.x

Guindon S. \& Gascuel O. 2003. A simple, fast, and accurate algorithm to estimate large phylogenies by maximum likelihood. Systematic Biology 52: 696-704. http://dx.doi.org/10.1080/10635150390235520

Hassouna M., Michot B. \& Bachellerie J.P. 1984. The complete nucleotide sequence of mouse 28SRNA gene. Implications for the process of size increase of the large subunit rRNA of higher eukaryotes. Nucleic Acids Research 12: 3563-3583. http://dx.doi.org/10.1093/nar/12.8.3563

Heled J. \& Drummond A.J. 2010. Bayesian inference of species trees from multilocus data. Molecular Biology and Evolution 27: 570-580. http://dx.doi.org/10.1093/molbev/msp274

Ilves K.L., Huang W.E.N., Wares J.P. \& Hickerson M.J. 2010. Colonization and/or mitochondrial selective sweeps across the North Atlantic intertidal assemblage revealed by multi-taxa approximate Bayesian computation. Molecular Ecology 19: 4505-4519. http://dx.doi.org/10.1111/j.1365-294X.2010.04790.x

Ino T. 1953. Ecological studies of Turbo cornutus Solander. 1. Changes of the spines on the shell due to environments. Bulletin of the Japanese Society for the Science of Fish 19: 410-414.

Isaac N.J.B., Mallet J. \& Mace G.M. 2004. Taxonomic inflation: its influence on macroecology and conservation. Trends in Ecology \& Evolution 19: 464-469. http://dx.doi.org/10.1016/j.tree.2004.06.004

Johannesson K., Panova M., Kemppainen P., André C., Rolán-Alvarez E. \& Butlin R.K. 2010. Repeated evolution of reproductive isolation in a marine snail: unveiling mechanisms of speciation. Philosophical Transactions of the Royal Society B 365: 1735-1747. http://dx.doi.org/10.1098/rstb.2009.0256

Johnson S.B., Warén A., Tunnicliffe V., van Dover C., Wheat C.G., Schultz T.F. \& Vrijenhoek R.C. 2015. Molecular taxonomy and naming of five cryptic species of Alviniconcha snails (Gastropoda: Abyssochrysoidea) from hydrothermal vents. Systematics and Biodiversity 13: 278-295. http://dx.doi. org/10.1080/14772000.2014.970673

Jovelin R. \& Justine J.L. 2001. Phylogenetic relationships within the Polyopisthocotylean monogeneans (Plathyhelminthes) inferred from partial 28S rDNA sequences. International Journal for Parasitology 31: 393-401. http://dx.doi.org/10.1016/S0020-7519(01)00114-X

Kemppainen P., Lindskog T., Butlin R. \& Johannesson K. 2010. Intron sequences of arginine kinase in an intertidal snail suggest an ecotype-specific selective sweep and a gene duplication. Heredity 106: 808-816. http://dx.doi.org/10.1038/hdy.2010.123

Knowlton N. 2000. Molecular genetic analyses of species boundaries in the sea. Hydrobiologia 420: 73-90. http://dx.doi.org/10.1023/A:1003933603879

Kurihara T., Shikatani M., Nakayama K. \& Nishida M. 2006. Proximate mechanisms causing morphological variation in a turban snail among different shores. Zoological Science 23: 999-1008. http://dx.doi.org/10.2108/zsj.23.999

Lester S.E., Ruttenberg B.I., Gaines S.D. \& Kinlan B.P. 2007. The relationship between dispersal ability and geographic range size. Ecology Letters 10: 745-758. http://dx.doi.org/10.1111/j.1461$\underline{0248.2007 .01070 . x}$

Librado P. \& Rozas J. 2009. DnaSP v5: a software for comprehensive analysis of DNA polymorphism data. Bioinformatics 25: 1451-1452. http://dx.doi.org/10.1093/bioinformatics/btp187

Monaghan M.T., Wild R., Elliot M., Fujisawa T., Balke M., Inward D.J.G., Lees D.C., Ranaivosolo R., Eggleton P., Barraclough T.G. \& Vogler A.P. 2009. Accelerated species inventory on Madagascar 
using coalescent-based models of species delineation. Systematic Biology 58: 298-311. http://dx.doi. org/10.1093/sysbio/syp027

Moore A.C., Burch J.B. \& Duda Jr T.F. 2015. Recognition of a highly restricted freshwater snail lineage (Physidae: Physella) in southeastern Oregon: convergent evolution, historical context, and conservation considerations. Conservation Genetics 16: 113-123. http://dx.doi.org/10.1007/s10592-014-0645-5

Palumbi S.R., Martin A., Romano S., McMillan W.O., Stice L. \& Grabowski G. 1991. The Simple Fool's Guide to PCR. University of Hawaii Press, Honolulu.

Paradis E., Claude J. \& Strimmer K. 2004. APE: analyses of phylogenetics and evolution in R language. Bioinformatics 20: 289-290. http://dx.doi.org/10.1093/bioinformatics/btg412

Pons J., Barraclough T., Gomez-Zurita J., Cardoso A., Duran D., Hazell S., Kamoun S., Sumlin W.D., Vogler A.P. \& Hedin M. 2006. Sequence-based species delimitation for the DNA taxonomy of undescribed insects. Systematic Biology 55: 595-609. http://dx.doi.org/10.1080/10635150600852011

Puillandre N., Cruaud C. \& Kantor Y.I. 2010a. Cryptic species in Gemmuloborsonia (Gastropoda: Conoidea). Journal of Molluscan Studies 76: 11-23. http://dx.doi.org/10.1093/mollus/eyp042

Puillandre N., Modica M.V., Zhang Y., Sirovich L., Boisselier M.C., Cruaud C., Holford M. \& Samadi S. 2012. Large-scale species delimitation method for hyperdiverse groups. Molecular Ecology 21: 26712691. http://dx.doi.org/10.1111/j.1365-294X.2012.05559.x

Puillandre N., SysoevA., Olivera B., CoulouxA. \& BouchetP. 2010b. Loss of planktotrophy, fragmentation and speciation: the deep-water gastropod genus Bathytoma (Gastropoda, Conoidea) in the western Pacific. Systematics and Biodiversity 8: 371-394. http://dx.doi.org/10.1080/14772001003748709

Rambaut A., Suchard M., Xie D. \& Drummond A. 2014. Tracer v. 1.6. Available from http://beast.bio. ed.ac.uk/Tracer [accessed 31 Jan. 2017].

R Development Core Team. 2012. R: a Language Environment for Statistical Computing. R Foundation for Statistical Computing, Vienna. Computer program. Available from http://www.R-project.org/ [accessed 8 Feb. 2017].

Salvini-Plawen L. \& Haszprunar G. 1987. The Vetigastropoda and the systematics of streptoneurous Gastropoda (Mollusca). Journal of Zoology 211: 747-770. http://dx.doi.org/10.1111/j.1469-7998.1987. $\underline{\text { tb04485.x }}$

Spalding M.D., Fox H.E., Allen G.R., Davidson N., Ferdaña Z.A., Finlayson M., Halpern B.S., Jorge M.A., Lombana A., Lourie S.A., Martin K.D., McManus E., Molnar J., Recchia C.A. \& Robertson J. 2007. Marine ecoregions of the world: a bioregionalization of coastal and shelf areas. Bioscience 57: 573-583. http://dx.doi.org/10.1641/B570707

Stadler T. 2009. On incomplete sampling under birth-death models and connections to the sampling-based coalescent. Journal of Theoretical Biology 261: 58-66. http://dx.doi.org/10.1016/j.jtbi.2009.07.018

Talavera G., Dincă V. \& Vila R. 2013. Factors affecting species delimitations with the GMYC model: insights from a butterfly survey. Methods in Ecology and Evolution 4: 1101-1110. http://dx.doi. org/10.1111/2041-210X.12107

Tamura K., Stecher G., Peterson D., Filipski A. \& Kumar S. 2013. MEGA6: molecular evolutionary genetics analysis version 6.0. Molecular Biology and Evolution 30: 2725-2729. http://dx.doi. org $/ 10.1093 / \mathrm{molbev} / \mathrm{mst} 197$

Vrijenhoek R.C. 2009. Cryptic species, phenotypic plasticity, and complex life histories: assessing deep-sea faunal diversity with molecular markers. Deep Sea Research II 56: 1713-1723. http://dx.doi. org/10.1016/j.dsr2.2009.05.016 
Weigand A.M., Jochum A., Pfenninger M., Steinke D. \& Klussmann-Kolb A. 2011. A new approach to an old conundrum - DNA barcoding sheds new light on phenotypic plasticity and morphological stasis in microsnails (Gastropoda, Pulmonata, Carychiidae). Molecular Ecology Resources 11: 255-265. http://dx.doi.org/10.1111/j.1755-0998.2010.02937.x

Williams S., Apte D., Ozawa T., Kaligis F. \& Nakano T. 2011. Speciation and dispersal along continental coastlines and island arcs in the Indo-West Pacific turbinid gastropod genus Lunella. Evolution 65: 1752-1771. http://dx.doi.org/10.1111/j.1558-5646.2011.01255.x

Williams S.T. 2007. Origins and diversification of Indo-West Pacific marine fauna: evolutionary history and biogeography of turban shells (Gastropoda, Turbinidae). Biological Journal of the Linnean Society 92: 573-592. http://dx.doi.org/10.1111/j.1095-8312.2007.00854.x

Williams S.T., Karube S. \& Ozawa T. 2008. Molecular systematics of Vetigastropoda: Trochidae, Turbinidae and Trochoidea redefined. Zoologica Scripta 37: 483-506. http://dx.doi.org/10.1111/j.1463$\underline{6409.2008 .00341 . x}$

Williams S.T. \& Ozawa T. 2006. Molecular phylogeny suggests polyphyly of both the turban shells (family Turbinidae) and the superfamily Trochoidea (Mollusca: Vetigastropoda). Molecular Phylogenetics and Evolution 39: 33-51. http://dx.doi.org/10.1016/j.ympev.2005.12.017

Zhang J., Kapli P., Pavlidis P. \& Stamatakis A. 2013. A general species delimitation method with applications to phylogenetic placements. Bioinformatics 29: 2869-2876. http://dx.doi.org/10.1093/ bioinformatics/btt499

Manuscript received: 1 February 2016

Manuscript accepted: 6 December 2016

Published on: 28 February 2017

Guest editors: Line Le Gall, Frédéric Delsuc, Stéphane Hourdez, Guillaume Lecointre

and Jean-Yves Rasplus

Desk editor: Danny Eibye-Jacobsen

Printed versions of all papers are also deposited in the libraries of the institutes that are members of the EJT consortium: Muséum national d'Histoire naturelle, Paris, France; Botanic Garden Meise, Belgium; Royal Museum for Central Africa, Tervuren, Belgium; Natural History Museum, London, United Kingdom; Royal Belgian Institute of Natural Sciences, Brussels, Belgium; Natural History Museum of Denmark, Copenhagen, Denmark; Naturalis Biodiversity Center, Leiden, the Netherlands.

Legend for Supplementary file. Specimens analyzed in the present study. Highlighted in bold characters: holotypes that have been observed (H obs) or sequenced (H seq); paratypes that have been observed (P obs) or sequenced (P seq); type localities represented by sequenced specimens (TL seq) or observed specimens (TL obs). 